\title{
Palabras ajenas para sentidos propios: El sentido muisca de la manta, el capitán y la luna a finales del siglo XVI*
}

\author{
Ana María Díaz Collazos**
}

\section{Resumen}

La sociedad colonial de finales del siglo XVI, en la región de Cundinamarca y Boyacá, utilizó las instituciones de la cultura indígena para arraigar su dominio. Por lo tanto, ciertos sentidos propios de la lengua y cultura muisca se anexaron a los sentidos de ciertas palabras de la lengua española. La palabra manta, por ejemplo, inspirada en el sentido español de cobija, pasa a designar cierta prenda de vestir de los indígenas con la carga valorativa que tenía en el esquema sociocultural tradicional. La palabra capitán sufre un cambio similar: al designar cierta autoridad local de los indígenas, queda integrada al sistema de jerarquías políticas y religiosas de la cultura regional autóctona, de tal modo que otros vocablos de la lengua española también sufren variación al designar elementos de ese sistema. Así mismo, algunos rasgos propios de la manera como se concebía el tiempo entre los indígenas, al coincidir con la de los españoles, pone de relieve ese aspecto lunar del paso de los meses como para que estos se denominen con la forma "una luna", "dos lunas", "tres lunas", etc.

* Resultado de investigación realizada en el Seminario Andrés Bello, Instituto Caro y Cuervo

** Licenciada en Literatura. Candidata a Magíster en Lingüística Instituto Caro Cuervo. adiazcoll@yahoo.com. 


\section{Palabras clave}

Léxico, semántica, español, muisca, colonia.

\section{Abstract}

The colonial society during the ends of 16th century in the region of Cundinamarca and Boyaca (today's provinces of the republic of Colombia) used certain Indian culture institutions in order to establish its domain. Therefore, certain senses from the muisca language and culture were added to the senses of some words in the Spanish language. The word manta, for example, is inspired in the Spanish sense of bedspread, and changes into appointing the dressing clothes of the Indians with the value that the traditional socio-cultural thinking placed on. The word capitan experiences a similar change: while it meant a war chief in standard Spanish, it changes into appointing an Indian local authority, so that it is integrated into the politic and religious system in the regional culture. This makes different related words from the Spanish language experience a similar change as they designate elements from that system. Similarly, some typical features of the comprehension of the time among Indians highlight the lunar aspect of the months, as for them to be named with the words una luna (one moon), dos lunas (two months), tres lunas (three months), etcetera.

\section{Key words}

Vocabulary, semantics, Spanish, Mwiska, colonial period.

\section{Introducción}

El español sin papa, arepa, chocolate, y aguacate sería un idioma sin sabor, sin mohán sería un idioma sin emoción, y sin chichicuilote o sinsonte un idioma sin música. Sin la palabra coca, quién sabe cómo se denominaría una de las 
marcas más famosas del mundo, y sin la palabra chicle no sabríamos qué mascaríamos contra el mal aliento. La lista de voces que el español tomó de las lenguas aborígenes americanas es larga e insospechada. Pero más insospechada aún es la lista de palabras netamente españolas que tomaron ciertos rasgos semánticos de la lengua y la cultura aborigen.

Este tipo de palabras no se dejan ver muy fácilmente en su relación con la lengua indígena por la apariencia de su forma significante. Si tomamos el caso de Colombia, aún cuando todavía se hablaba la lengua muisca, se registran términos en español cuyo contenido semántico de influencia indígena es poco visible. En realidad los hablantes del español no veían la necesidad de admitir el préstamo léxico cuando la lengua española ofrecía los recursos para referirse a una realidad que tenía nombre en la lengua indígena. Sin embargo, esa otra lengua estaba ahí presente, aunque de manera silenciosa, expresando sus realidades desde lo profundo de la relación.

Existe un registro muy amplio de todas estas relaciones en los documentos que reposan en los archivos. Es cierto que las Crónicas de Indias ofrecen un corpus muy copioso para los estudios lingüísticos, pero más útiles para entender el habla coloquial de las personas son los documentos de los archivos. Allí es posible encontrar el registro de los juicios, que reflejan el carácter de la interacción oral en los tribunales. Aunque los escribanos eran quienes, en su mayoría, redactaban los testimonios de las personas, el documento escrito era producto de esa interacción y, por tanto, reflejo de las palabras expresadas oralmente por los testigos. Los documentos de archivo constituyen, pues, la fuente primaria para la recolección del léxico en el cual se inspira este artículo.

El presente trabajo es, entonces, un comentario lingüístico sobre esas palabras que se usaban en el léxico de finales del siglo XVI y que servían para expresar sentidos de las lenguas indígenas, en la región de Cundinamarca y Boyacá. Se enmarca dentro de un trabajo más amplio que se elaboró en el contexto de la cátedra de lexicografía, en el Instituto Caro y Cuervo, maestría en Lingüística Española, año 2006. Se recogió el material lingüístico del Archivo General de la Nación, ubicado en Bogotá, entre los años de 1563 y 1588: veinticinco años después de la fundación de Bogotá. En 1563 ya ha 
transcurrido un lapso de tiempo como para que una generación haya adquirido los caracteres peculiares de su habla, y a partir de allí se cuentan otros veinticinco años para este corte sincrónico. Sin embargo, este comentario se basa en de 1586, de 1578 y de 1569, producidos en la ciudad de Bogotá. A ella confluían hablantes de los municipios circunvecinos para ser atendidos en sus conflictos jurídicos, así que el registro de habla es el de la región que tiene como eje de dominio Bogotá y no Bogotá exclusivamente, denominada Santafé en ese entonces.

Las palabras objeto de análisis son representativas del campo semántico del vestido, de la política y del tiempo: manta, capitán y luna respectivamente. Ellas se relacionan con otras de su campo semántico, así que en cada apartado se establecerán los lazos con otras formas léxicas que forman parte de una red de significación originada en América por el contacto con las lenguas indígenas.

Para encontrar el rasgo semántico particular dado por la lengua aborigen, se debe corroborar que éste no se encuentre en el español oficial de la Península. Para ello, se debe comparar con la definición de un diccionario de la época. Sebastián de Covarrubias publica en España un diccionario de la lengua española, en 1610, llamado Tesoro de la lengua castellana o española. Allí se documentan los términos plenamente aceptados por el léxico oficial de la península, y es el que se utiliza como parangón.

Se recogen algunas citas de los documentos coloniales en el corte sincrónico establecido, para mostrar el contexto verbal en que se usaban las palabras objeto de análisis. Algunos de estos documentos se encuentran inéditos, por lo que las citas son transcripciones hechas por el autor del presente artículo. Entre los que se encuentran publicados, están los que recoge Hermes Tovar Pinzón (1995) y Pablo Rodríguez (2000). De manera que se respeta el texto tal cual dichos autores lo transcribieron.

Se analiza cada palabra en relación con su contexto verbal, para verificar los rasgos semánticos que presenta, en su diferencia y semejanza con los que recoge Covarrubias en su diccionario. Para verificar tales rasgos, se 
utilizan también las investigaciones de expertos. De gran importancia es el trabajo que hace Maria Stella González de Pérez (1987), una transcripción paleográfica de un manuscrito del siglo XVII:Diccionario y gramática chibcha. El original reposa en la Biblioteca Nacional y no tiene fecha ni nombre de autor, pero parece haberse escrito entre 1605 y 1620 . Según el estudio de González de Pérez, es un manual elaborado por un sacerdote para enseñar a los evangelizadores la lengua de los evangelizados, en este caso la lengua muisca. Todos estos estudios respecto a la cultura, la historia y la lengua muisca sirven para determinar su injerencia en el cambio semántico que sufre una palabra del español.

\section{La manta muisca: ¿vestido o sobrecama?}

Covarrubias define la palabra manta como"la cobertura ordinaria de la cama", la cual dista mucho del sentido con que se usa en los documentos de finales del siglo XVI. En ellos, se mencionan una amplia gama de clases de mantas, como mantas de la marca, mantas de maure o mantas de pincel.

Un documento de 1586 registra un juicio seguido a cierta india llamada Catalina, supuestamente por haberle robado a la india Juana una caja llena de ropa. Según la querella que interpone la india Juana, la caja contenía estos elementos, entre otros:

Primeramente una manta de pinzel muy Buena -

$\sim$ otra manta colorada -

$\sim$ otra manta blanca -

una líquida de tafetán-

una camissa labrada en seda amarilla es de rruan

otra camissa blanca de rruan -

$\sim$ unos calçones de paño negro guarneçido con otro de pelo negro

$\sim$ tres baras de rruan - 
$\sim$ bara y media de olanda -

tres o quatro Honças de todas colores de seda -

(A.G.N., Caciques e Indios, 1586: leg. 38, fol. 226)

Aunque otros elementos se refieren en la querella, durante el juicio se alude constantemente a la ropa. Por ejemplo, en una petición que la india Juana extiende a las autoridades, dice: "joana yndia ladina e (n) la querella que tengo dada de catalina sobre averseme quedado con una caxa de rropa digo que yo tengo dada ynformaçion bastante de lo contenido en la dicha querella" (1586: 31r). En el testimonio que se registra de la india Catalina, la inculpada, se dice "fue ella para dicha caxa e rropa que en ella estava" (1586: 232v). En el testimonio que se registra del indio Andrés, se dice: "este t (es) tigo ha visto que la dicha joana yndia tenya una caxa de rropa de su bestir donde la tenya guardado con su llave" (1586: 228r).

En el juicio, pues, lo que se reitera como objeto de robo es la ropa que estaba en la caja. Es decir, las prendas de vestir son objetos tan valiosos, que por ellos se hacen juicios y se enfatiza la gravedad que representa el hurto de ellas. El clima de la región es frío y la pérdida de la ropa representa un daño a la persona, pero hay algo en las mantas que las hace valiosas. Para determinar ese algo, debemos recurrir a otros documentos y a los estudios de los historiadores.

El sentido de la palabra manta apunta a una prenda de vestir compuesta de una sola pieza que se ajusta anudándola a uno de los hombros y cubre el cuerpo al menos hasta las rodillas. Mide generalmente 186 × $186 \mathrm{cms}$. El material usado para el tejido de la manta era el algodón, cuyo color natural podía ser blanco, amarillo pálido o pardo (MARTíNEZ CARREÑO, 1995: 59). Así pues, se puede pensar que las mantas blancas mencionadas en el documento son aquellas que no habían recibido ningún pigmento en la superficie. Las mantas coloradas posiblemente no se refieran a que fueran de color rojo. Si se toma "colorada" como participio de "color", entonces podría estar designando ciertas mantas que hubieran recibido algún tipo de pigmento, sin que éste fuera muy sofisticado. 
En otro documento, de 1578, se manifiesta que un impuesto llamado demora se paga en oro y también en mantas: "En esta manera por santo ju (rament) o paga tres veyntes y medio de oro en un $t$ (erc)io del oro que funden aquí en su pueblo y mas quinze pesos por ser el oro bajo y para pagar el quinto al rey y mas de treynta y çinco mantas de la marca y otro tanto como esto pagan por navidad" (A.G.N., Caciques e Indios, 1578: leg. 32, fol. 224v). Si el impuesto se paga en mantas, y no solamente en oro, se sospecha sobre el valor de la manta como instrumento de intercambio similar a la moneda.

Esto es coherente con la situación socioeconómica del momento en el que el oro empezaba a escasear y el colonizador debía arraigar su poder con otros mecanismos de dominio como lo fue la encomienda (TOVAR, 1995: 25). Ésta era una institución que obligaba a los indígenas, entre otras cosas, a pagar al encomendero la demora. La ambición por el oro de los españoles empezaba a ceder espacio a los objetos que ya en la cultura autóctona tenían un valor social muy alto. Por lo tanto, la palabra manta es más que la alusión a una prenda de vestir, es la alusión a una especie de moneda o instrumento de intercambio comercial por el alto valor que tenía para los muiscas.

Conviene citar un estudio de Emilia Cortés Moreno (2005) en el que se presenta un cotejo de una investigación arqueológica con los testimonios de dos documentos de 1592 y 1593, constancias de pago de los indígenas de Oicatá, provincia de Tunja. Cortés Moreno se refiere un trabajo arqueológico en el que se reconstruyó una prenda de vestir mediante el uso de varios trozos de tela procedentes de la zona muisca. Gracias a la detallada elaboración del dibujo, es posible armar el rompecabezas y encontrar un ejemplar de una de las llamadas mantas de la marca. Que este ejemplar corresponde a una manta de la marca se sabe por los documentos de archivo que se utilizan para el cotejo.

Hermes Tovar Pinzón concuerda con que las mantas se usaban de diferente clase según el estatus de quien la llevara y la ocasión social (TOVAR, 1995: 45), así que las llamadas mantas de la marca eran probablemente las que se elaboraban para personas de alta posición en la jerarquía indígena. 
En el documento de la india Juana se relaciona una manta de pincel. No se dice de la marca, sino de pincel. Se ha dicho que el detalle en el dibujo en las de la marca hace pensar que muy seguramente se pintaban, si no con pincel propiamente dicho, con un objeto de finura similar. Sin embargo, el documento del juicio contra la india Catalina (1586) menciona una manta de pincel y no de la marca, o sea, habría alguna diferencia. Es posible que fuera una diferencia en el tipo de dibujo o en el estilo de tejido que no resulta muy claro en el documento.

En un testamento de 1567, oficiado por un escribano de nombre Francisco de Salazar para una india llamada Inés, se dice: "Iten me debe el cacique de Subachoque dos mantas chingas de unas que ha días le vendí" (RODRÍGUEZ, 2002, 1567: 26). Según Emilia Cortés (2005), en oposición a la manta de la marca está la manta chinga. En la última edición del Diccionario de la Real Academia (2003) se documenta chinga como una prenda corta en general. Chinga sí es una palabra de procedencia indígena, que en los documentos se usa como adjetivo para mantas. Entonces es posible deducir una evolución de la expresión mantas chingas en la que chingas se refiere a las mantas más cortas, razón por la cual eran las de menor valor, y en la que se mantuvo el adjetivo para referirse a las prendas de vestir de esta característica.

En el testamento del indio Juan, de Engátiva, redactado por el escribano Sancho López en 1578, se registra manta de maure: "Iten declaro que un indio de Pasca llamado Guacha me tiene en su poder una manta de maure" (RODRÍGUEZ, 2002, 1578: 31). Sobre la manta de maure, se dice que es una voz de origen cumanagoto (PATIÑO, 1995: 39) que se refiere a cierta faja de algodón. Cuando se une a la palabra manta, se refiere entonces a la faja o cinturón que sirve para ceñirla a la cintura (CARREÑO, 1995: 60-61).

En el documento que se cita al comienzo de este apartado (querella de la india Juana, juicio contra Catalina) se menciona una líquida de tafetán. El nombre de la tela, tafetán, es español; el de la prenda, líquida, también parece español, pero líquida es una variante de líquira, del quechua Iliclla, Ilijilla, líquilla, Ilica, Ilicllita (RODRÍGUEZ DE MONTES, 1987: 111). En los otros renglones se reitera manta blanca y manta colorada, así que si líquida fuera un adjetivo 
debería añadirse manta líquida. Así que es un sustantivo:"era una manta que puesta sobre los hombros bajaba hasta la rodilla, prendiéndose con un topo a la altura del pecho" (RODRÍGUEZ, 1987: 112). Por analogía con la palabra española, el escribano que toma la querella a la india escribe líquida.

Con todo esto vemos cómo una palabra que designaba la tela que servía para cubrir la cama adquiere un nuevo sentido. En los documentos ya la palabra tiene el sentido pleno de prenda de vestir y no el que se documenta en Covarrubias. Además, la manta como objeto valioso entró al acerbo de la lengua española de tal forma que se combina con otras palabras para establecer tipologías dentro de la misma categoría. Estas tendrían una correspondencia con las jerarquías sociales propias de los muiscas. Por lo pronto, puede proponerse la siguiente gradación, de más a menos en la jerarquía:

1. Manta de la marca.

2. Manta de pincel.

3. Manta colorada.

4. Manta blanca.

5. Manta chinga.

En la época del Diccionario y gramática chibcha ya la palabra manta como prenda de vestir se encuentra estabilizada. El autor de esta Gramática, para ejemplificar el uso del posesivo en muisca, escribe:

Ze boi, mi manta

Vm boi, tú manta

Chi boi, nuestra manta

Mi boi, vuestra manta

A boi, su manta

(GONZÁLEZ DE PÉREZ, 1987, ¿11605-1620?: 74) 
El español no ingresa la palabra indígena boi en su forma léxica, pero sí en su contenido semántico con toda su carga valorativa. Algunas veces se habrá escuchado en las provincias de Colombia, acerca de los bogotanos, que exageran la valoración del vestido de manera especial (como si no ocurriera lo mismo en otras partes). Podría tener esta creencia alguna relación con la valoración que hacía el pueblo muisca y que luego fue aprovechada por los españoles para perpetuar su dominio en la región.

\section{El capitán o la "cuña del mismo palo"}

Guillermo Vanegas (1997) realiza un estudio sobre la forma como los españoles usaron el sistema de gobierno muisca para sus fines colonizadores. Aprovecharon la élite que ya existían en el pueblo indígena para, a través de ella, ejercer el control sobre los impuestos y la circunscripción territorial. De manera que allí se aplica el refrán no hay cuña que más apriete que la del mismo palo, puesto que los mismos indígenas sirvieron al sistema colonial para su propia opresión. Así pues, las palabras españolas para nombrar las autoridades indígenas encierran matices semánticos tanto de la lengua española como de la indígena.

Sebastián de Covarrubias define la palabra capitán así:"el que tiene por mando una compañía de soldados". El capitán es una autoridad de la guerra, pero en los documentos coloniales se tiende a perder el aspecto bélico, para referirse a cierta autoridad política de los indígenas. Véase, por ejemplo, un texto correspondiente a un interrogatorio que responde el indio Alonso y que registra el escribano Francisco de Santiago. Este texto está catalogado con el título "Autos en razón de prohibir a los caciques de Fontibón, Ubaque y otros no hagan fiestas, borracheras y sacrificios de su gentilidad":

y todos los más yndios y yndias ladynos y cristianos hazen santuaryos y el dy a de oy mijor q (ue) prymero q (ue) fuesen crystyanos todo por consejo de los geques y santeros y q (ue) ansy mysmo los caçyques y capitanes tyenen unos buhíos cada uno por sy q (ue) llaman quca donde meten a sus sobrynos y $q$ (ue) ally ban cada noche los santeros 
a predicarles y enseñarles y les dicen $q$ (ue) no crean a los padres de la dotryna $q$ (ue) todo lo $q$ (ue) dicen es mentyra y que ellos les dicen verdad y $q$ (ue) miren a lo $q$ (ue) fueron sus antepasados y que hagan como ellos hiçieron muchos y grandes sacrefiçios y santuarios y $q$ (ue) miren q (ue) muchos yndios bajos por hazer santuaryos bynyeron a ser rrycos y grandes capytanes quanta mas ellos q (ue) lo ofrezcan al santuario y que ellos ansy lo hazen y q (ue) quando ally salen sus tyos les sacan con gran fiesta (y)// hazen borrachera $y$ santuaryo por su salyda $q$ (ue) ansy mysmo los caçiques hazen sacrefyçio mandandolo hazer a sus geques $y$ santeros $q$ (ue) son seys santeros de cada caçique grande $y$ de cada capitán uno y dos sy es capytan grande y $q$ (ue) sacryfican uno o dos muchachos y estos an de ser estrangeros $y$ los deguellan como carneros toman la sangre en un hoyo pa ( $\mathrm{ra}$ ) $q$ (ue) ally la beba el demonyo y el querpo unos los ponen en sus santuariyos y otros los entyerran en los enterramyentos de los caciques y luego por la mañana senbyjan las cabezas y el querpo todos los $q$ (ue) ofrecen al cacique pa ( $r a$ ) el santuaryo y hazen una borrachera solene por el sacrefyçio $q$ (ue) hyçieron al santuaryo y dizen $q$ (ue) hazen borrachera por algún buhyo o çercado nuevo que hyçieron por $q$ (ue) los españoles ni la justiçia no lo sepan y es por el sacrefyçio $q$ (ue) hyçieron (A.G.N., leg. 27, 664r-664v, en TOVAR, 1995: 258-259).

Se observa en el texto una distinción entre dos categorías: jeques y santeros, por un lado, y caciques y capitanes, por otro. Estos últimos son los que ordenan a sus sobrinos que vayan a la quca, palabra de origen indígena para denominar el santuario donde los jóvenes eran adoctrinados por los jeques y santeros. Así pues, se nota la distinción entre dos tipos de autoridades: los que mandan y los que adoctrinan: la autoridad civil y la autoridad religiosa. De hecho, en el pueblo muisca existía esta distinción, y no la "encarnación del poder político y religioso en un solo individuo" (TOVAR PINZÓN, 1995: 68-69).

Según el historiador Tovar Pinzón, los santeros y jeques son autoridades religiosas con funciones específicas. Mientras los santeros eran líderes espirituales más cercanos a la comunidad y que servían como mediación entre lo 
humano y lo divino, los jeques estaban más relacionados con lo puramente ritual hacia los dioses. De hecho, en el fragmento citado se dice que los santeros eran quienes predicaban a los sobrinos de los caciques, por lo que su función estaba más bien asociada a la enseñanza y preservación de la doctrina en el pueblo como tal.

Los santeros, entonces, estaban subordinados a la autoridad civil, representada en caciques y capitanes. El fragmento citado indica que cada cacique tenía seis santeros a su servicio, y que cada capitán tenía dos de ellos. De lo cual se infiere que los caciques eran autoridades de rango superior a los capitanes. Los capitanes, a su vez, están jerarquizados en capitán y capitán grande.

Si confrontamos esto con la traducción de la palabra capitán en Diccionario y gramática chibcha, encontramos:

Capitanía. Zibyn.

Capitán. Zibyntyba.

Capitanía menor. Uta.

Capitán menor. Uta [o] tybargue.

(GONZÁLEZ DE PÉREZ, 1987, ¿̇1605-1620?: 209)

Capitán es una forma lingüística española para nombrar una autoridad local subordinada al cacique que los colonizadores aprovecharon para sus propósitos, como la recolección de impuestos y el control sobre ellos. Así lo corrobora Guillermo Vanegas:

Entre los muiscas, la unidad de organización social estaba constituida por las "capitanías o "parcialidades", grupos de filiación matrilineal exógamos, que de acuerdo con su jerarquía y tamaño podían denominarse uta (capitanía menor) y sybyn (capitanía mayor). (...) Un conjunto de "capitanía" constituía una unidad mayor que los españoles llamaron "pueblo" o "cacicazgo" (...) Las capitanías estaban sujetos a la autoridad de los llamados "capitanes", que podían ser 
Las capitanías formaban parte de entidades territoriales mayores que eran los cacicazgos, estos ya gobernados por un cacique. Esta división territorial propia del pueblo muisca fue aprovechada por los españoles para organizar su propio dominio sobre el mismo. Es así como los nombres españoles para referirse a las autoridades indígenas están integrados al sentido que esos nombres tenían para el pueblo aborigen, aunque ya en el contexto del régimen colonial. La palabra capitán no significa necesariamente un dirigente de ejércitos, sino un dirigente civil que podía o no tener funciones militares. Es decir, la restricción de la palabra está dada por su alcance en el campo de lo administrativo y no de lo bélico. La distinción entre capitán y capitán grande, entonces, también usa estos adjetivos españoles para nombrar estas autoridades según la extensión de su poder.

La palabra jeque, con sus variantes xeque y geque, tiene sus orígenes en lengua árabe y sirve para denominar ciertas autoridades de este pueblo. Sebastián de Covarrubias (1610) lo define así:"en lengua Arábiga vale hombre anciano, Alcayde, señor de vasallos. Diego de Urrea, dize que vale tanto como que es caudillo de gente, del verbo xeieche, que significa envejecer, porque son los mas ancianos, y honrados entre todos".

En el imaginario español posterior a la reconquista, fundada en las adhesiones religiosas de los pueblos en lucha, el enemigo del cristianismo era el Islam. De ahí que existiera una asociación entre lo que no es cristiano y lo árabe, que quizás terminaría por usar el nombre de la autoridad islámica para la indígena.

En el mismo sentido, Juan de Castellanos expresa:

Y concluidos los días del ayuno que llaman saga, luego dan al xeque aquello que han de dar al Santuario, 
y el xeque, no con menos abstinencia,

ofrece la presea, consultando

con el demonio lo que se pretende

por parte del que dio la tal ofrenca

al cual después el xeuqe le da cuenta

de aquello que el diablo le responde

(CASTELLANOS, 1997. 1589: Parte 4, Canto 1,1160)

Sebastián de Covarrubias (1610) define la palabra santero como "El medio hermitaño que tiene a su cuenta la custodia, limpieza y adorno de alguna hermita, y de pedir para azeite con que arda la lampara". Es decir, es un intermedio entre el sacerdote y el devoto.

El santero al que se refiere en el documento no le rinde culto a las imágenes de los santos, sino a las divinidades no cristianas. De esta manera, la palabra conserva parte de su sentido, pero adquiere uno nuevo cuando se aplica a una categoría de líder espiritual que existe en la cultura indígena.

\section{Una, dos, tres lunas}

En los documentos de finales del siglo XVI es frecuente encontrar la expresión "una luna" para referirse al lapso de tiempo aproximado a un mes. En el juicio de la india Catalina por haberle robado la ropa a la india Juana, se documenta la expresión en este sentido, cuando se llama a la india Luisa como testigo:

que abra una luna poco mas o menos que estando esta testigo en la casa de la dicha juana que se avia venydo alquilar a esta çiudad la dicha joana que via ir se como se fue fuera desta çiudad y rrogo a esta testigo que le llevara una caxa pequena la que tenia su rropa a casa de [tachado=ilegible] catalina (A.G.N., Caciques e Indios, 1586: leg. 38, 229r). 
En el testimonio del indio Alonso, que registra el escribano Francisco Santiago y que está catalogado como "Autos en razón de prohibir a los caciques de Fontibón, Ubaque y otros no hagan fiestas, borracheras y sacrificios de su gentilidad", se documenta también:"agora poco más abrá de una luna q (ue) se muryreron dos capitanes de Suba" (A.G.N., leg. 27, 664r-664v, en TOVAR, 1995: 258-259).

El Corpus Histórico de la Real Academia no registra la expresión una luna con el sentido de un mes en documentos anteriores a finales del siglo del XVI. Es cierto que existía un conocimiento de la relación entre las fases de la luna y otros sistemas de contar el tiempo, diferentes del calendario romano. Sin embargo, lo que no existía era el uso de una luna como expresión fija para nombrar el mes. Entre los primeros registros se cuentan varios cronistas de Indias, entre ellos Fernández de Oviedo:

La tierra de aquellas minas es sosa, y como movediza hasta donde se topa la veta, la cual siguen cavando con sus coas, que son palos agudos, puntiagudos, de buena y recia madera; e así sacan las esmeraldas que hallan, y es la veta a manera de greda. Y para esta labor les ha enseñado el demonio una manera de religión vana, como en otras cosas y hechicerías; $y$ es que toman ciertas hierbas con que dicen que saben en qué veta hallarán mayores piedras y mejores. Otros indios de otra parte ninguna, como sea de fuera del señorío de Somindoco, que es el cacique y señor de las minas, no puede ir a buscar esmeraldas, ni aun osan ver las minas; porque dicen ellos que se mueren dentro de una luna, que es un mes o treinta días. Así que, por temor desa falsa opinión, no entiende otra gente en el ejercicio del sacar esmeraldas (1535-1557).

Y también:

En la tierra de Tunja, las personas principales e otros capitanes que entre ellos tienen preeminencia, no se entierran sino así como agora diré. Ponen sus cuerpos, con todo el oro que tienen, en sus santuarios 
y casas de oración, en ciertas camas que los españoles allá las llaman barbacoas, que son lechos levantados sobre la tierra en puntales; e allí se los dejan con todas sus riquezas pegadas ojunto al cuerpo muerto.

En lo demás, la una provincia y la otra tienen una mesma manera de gente, como está dicho; y ambas generaciones son gente de mucha contractación, y hacen sus mercados en cada pueblo, a los cuales va mucha gente a comprar y vender, y hacer sus ferias e truecos en días señalados cada pueblo, como en España. Cuando los de una provincia déstas, o los panches, quieren hacerse guerra, una luna o un mes están primero cantando o rogando al sol, que tienen por su Dios, que les de vitoria; y su aquellos sus cantares le dicen la causa que les mueve para la guerra que quieren emprender, sin la cual diligencia no la comienzan, sin la justificar primero con el que ellos tienen por su Dios. La guerra que hacen, es peleando y matando los unos a los otros, y los que quedan vencedoras, queman los pueblos a los vencidos, y cautívanles sus mujeres, y tómanles el oro y cuanto tienen (1535-1557).

Los textos citados muestran que en español no se usaba el término "luna" para contabilizar los meses, pues Oviedo debe añadir una breve explicación "una luna o un mes", o "una luna, que es un mes o treinta días". En Oviedo, la alusión coincide con el territorio muisca, pero en Cartagena la registra Boyd-Bowman en 1537.

Se tienen noticias de la división del tiempo muisca en lunas, como lo dice Pedro Simón citado por Ghisletti sobre los muiscas: " (...) los meses contaban por lunas con sus menguantes y crecientes, dividiendo cada una de estas dos en otras dos, con que venían hacer cuatro partes del mes, o la luna al modo que nosotros lo dividimos por cuatro semanas; tenían también año de 12 meses o lunas (...)" (GUISLETTI, 1954: 191-192).

El Diccionario y gramática chibcha recoge la entrada luna con su equivalencia en muisca chie. La misma palabra tiene equivalencia con luz, lustre o resplan- 
dor (GONZÁLEZ, 1987, ¿1605-1620?: 275). Además, la entrada mes equivale a chie igualmente (GONZÁLEZ, 1987, ¿1605-1620?: 279). Estas equivalencias permiten inferir que hay una misma palabra muisca para referirse a la luna, la luz que emite y el tiempo transcurrido en todas sus fases, que un lapso de cuatro semanas Las fases de la luna son diferentes estadios de su luminosidad y la sucesión de un ciclo de fases lunares permite contabilizar el tiempo.

El término español una luna puede ser derivado de una forma muisca de contabilizar el tiempo. En el documento citado del testimonio de Luisa, en el juicio contra Catalina, se dice: "poco más abrá de una luna", en el que una luna parece referirse al transcurso de las cuatro semanas, pero se añade las palabras poco más, es decir, unos días más. Con estos días de más se acerca al mes occidental, que tiene treinta días. Así pues, una luna indica el transcurso de los veintiocho días en el sistema muisca y poco más abrá de una luna indica el transcurso de aproximadamente treinta días. La expresión completa, pues, parece referirse a un lapso de tiempo que se aproxima a un mes occidental.

\section{Conclusión}

El régimen colonial no podía instaurar un sistema de control totalmente nuevo sobre los pueblos sometidos, sino aprovechar en parte el que ya había. Algo parecido ocurre con la lengua: las palabras no podían imponer la totalidad de los sentidos derivados de la tradición española. los sentidos, valoraciones y jerarquías de la lengua indígena terminan por deslizarse soslayadamente en el espectro semántico de esos vocablos españoles. Es cierto que este fenómeno muestra cómo la subordinación de la lengua indígena favorecía el éxito del español como sistema, pero en su historia hay momentos en los que sucumbe la relación con la lengua subordinada.

\section{Bibliografía}

"Autos en razón de prohibir a los caciques de Fontibón, Ubaque y otros no hagan fiestas, borracheras y sacrificios de su gentilidad". 1563-1569. Transcripción de Hermes Tovar Pinzón. (1995). Relaciones y visitas a los 
Andes: siglo XVI. Región Centro-Oriental. Bogotá: Instituto Colombiano de Cultura Hispánica, pp. 239-266.

CASTELLANOS, Juan de. (1997). Elegías de varones ilustres de indias. 1589. Edición de Gerardo Rivas Moreno. Cali: Fundación para la Investigación y la Cultura.

CORTÉS MORENO, Emilia (2005). Mantas muiscas. Boletín Banco de la República Bogotá: Banco de la República, mayo 16, <www.lablaa.org >.

COVARRUBIAS, Sebastián de. (2003). Tesoro de la lengua castellana: facsímil de la edición de 1673. 1610. Madrid: Biblioteca Virtual Miguel de Cervantes, <http://www.cervantesvirtual.com/FichaObra.html ?Ref=18011>.

GONZÁLEZ DE PÉREZ, Maria Stella (transcripción y edición) (1987). Diccionario y gramática chibcha - Manuscrito anónimo de la Biblioteca Nacional de Colombia. ¿1605-1620? Bogotá: Instituto Caro y Cuervo.

GHISLETTI, Louis V. (1954). Los mwiskas: una gran civilización precolombina. Bogotá: Ministerio de Educación Nacional.

"Indios de Cuenca, encomienda de don Antonio Bermúdez, declaraciones que se tomaron en Santafé, sobre los tributos que le pagaban a dicho encomendero, a fin de justipreciar las ausaciones de don Pedro, cacique de dichos indios". Transcripción inédita por Ana María Díaz. Archivo General de la Nación, Fondo Caciques e Indios. (Legajo 32, Folio 185-293, Santafé, 14 de abril de 1578).

"Juana, india de Santafé, demanda por el hurto de su ropa, a Catalina, india de Chocontá". Archivo General de la Nación, Fondo Caciques e Indios. Transcripción inédita por Ana María Díaz. (Legajo 38, Folio 225-235, Bogotá, 1586).

MARTÍNEZ CARREÑO, Aída (1995). La prisión del vestido. Aspectos sociales del traje en América. Bogotá: Ariel. 
REAL ACADEMIA DE LA LENGUA ESPAÑOLA (2006). Corpus Histórico del Español. Página de la Real Academia de la Lengua Española (noviembre). $<$ www.rae.es $>$.

(2003). Diccionario de la lengua española. Madrid: RAE, 22a. ed.

RODRÍGUEZ DE MONTES, Maria Luisa (1987). Algunos quechuismos en el ALEC. Boletín del Instituto Caro y Cuervo, 42.1, Enero-Abril, 95-121.

"Testamento de Inés, india de Tunja". 1578. Transcripción de Pablo Rodríguez (2002). Testamentos indígenas de Santafé de Bogotá. Bogotá: Instituto Distrital de Cultura y Turismo, p. 34.

"Testamento de Juan, indio de Engátiva". 1580. Transcripción de Pablo Rodríguez. (2002). Testamentos indígenas de Santafé de Bogotá. Bogotá: Instituto Distrital de Cultura y Turismo, p. 43.

TOVAR PINZÓN, Hermes (Transcrip.) (1995). Relaciones y Visitas a los Andes. Región Centro Oriental. Siglo XVI. Bogotá: Instituto Colombiano de Cultura Hispánica.

VANEGAS MUÑOZ, Sayed Guillermo (1997). Cuña del mismo palo:participación de la élite indígena en las instituciones del Nuevo Reino de Granada (siglos XVII y XVII). Bogotá: Naidí. 